\title{
The historical potential of flux in this unique moment. Conceptually highlighting an opportunity for praxis-driven change
}

The second edition of a new journal is sometimes the toughest. The honeymoon excitement and energy of launching a brand new journal evaporates, and the journal is no longer new. It also does not help if you are trying to put together a second issue at the end of a semester and academic year, when many of us are in the middle of final exams, course assessment and thesis evaluations. And it really does not help if a global pandemic breaks out and turns higher education upside down in every way imaginable.

It is not our purpose in this editorial to make light of the health, economic, political, leadership, and public policy challenges facing the societies our higher education institutions serve. And it is especially not our intention to minimize the negative and tragic impacts experienced by so many across the globe, including our colleagues. Rather, we are interested in advancing an alternative angle for contextualizing these challenging times, along with suggesting a counterintuitive, praxis-driven contribution many of us are in the position to make, because we may be the last people on earth at risk, not the first.

When something of biblical proportions impacts lives, the moment-unless it is fatal-often offers a profound learning opportunity. The purpose of this editorial is to stress that we are now in such a moment and it is exceptionally easy to miss if we slip in to the $21_{\text {st }}$ century reflexive scholarly cliché of seeking attention instead of paying attention. In its most humorous, self-effacing form, this distinction is drawn by Joseph Gordon-Levitt in his 2019 Ted Talk, 'How Craving Attention Makes You Less Creative' (Gordon-Levitt, 2019). More seriously, however, thinkers like Newport (2016), Robertson (2018), and Shahjahan (2015, 2016, see Acknowledgements) make a disturbing case about the different ways $21_{\text {st }}$ century scholars now focus and spend so much time seeking attention that we may have forgotten to pay attention to the ideas and ideals that might matter the most. Therefore, the question we pose in this editorial is: what could we pay attention to, right now, if we more profoundly understood the historical juncture and the exceptional potential in this particular moment in time?

What might matter the most, in the midst of a generational challenge, is a once-in-a-lifetime opportunity for even asking this question. Some of us may have, if we want, time for fundamental, critical reappraisal and reflection across 
several levels of higher education. It is obvious to ask and hope, as many do, if higher education is up to this challenge in highly visible settings where gamechanging moves are being made by our colleagues in university hospitals and medical research labs where vaccines, therapeutics, and testing methods are born. The argument we underline to colleagues around the globe is that higher education might be what matters the most - in the long-run - in the analytically opposite corner, where everyone is not focused just now; in other words, where most scholars work, doing the jobs most scholars do, most of the time. For example, Angervall, Baldwin, and Beach, in this issue, focus on this by problematizing an unseen 'mission stretch' in teacher education. Through this, they are able to illustrate a growing gap, or what is described as 'two different worlds' between those who do research or those who primarily teach in teacher education.

Everyday challenges like these also concern the work of colleagues focused on the global, transnational tensions we outlined in our inaugural editorial 1 (Aarnikoivu et al., 2019). None of those tensions have gone away, as the 2020 global protests focused on policing and endemic structural racism have vividly underlined. Moreover, the tensions may have become exacerbated by the current pandemic and associated economic shockwave. Those twin global stresses are likely to trigger challenges to assumptions about higher education from all quarters, not all of them friendly. That acknowledged, we would argue that challenging assumptions is never a bad thing, as most of the tensions we highlighted in our first editorial need unconventional, not conventional engagement.

In this issue, Fagrell, Fahlgren and Gunnarsson suggest precisely this when it comes to rethinking the role of higher education's most important stakeholders, while Clarence, also in this issue, focuses on the specific context of postgraduate education. In the latter paper, the need for attending to/engaging with the affective dimension of academic writing is also highlighted. If we are paying attention, just now, we might recognize that this is actually the ideal time for action and asking what higher education could be in the $21_{\text {st }}$ century, post pandemic.

The reason we may not see a far more interesting $21_{\text {st }}$ century focus on what we could do is frankly because we are still mired in $18_{\text {th }}, 19_{\text {th }}$, and $20_{\text {th }}$ century liberal and neoliberal Eurocentric, US, or Anglo-centric preoccupations with what we all should be doing, which is a completely different question. The ever-present tension between a curiosity-driven could and morally or pragmaticallygrounded should often obscures our greatest potential contribution, as an institution that not only can build vaccines in the middle of a pandemic, but saw the pandemic coming, knew what to do, and even anticipated events like this in global health (university) programs around the world. That reality is easy to miss, but it is also worth thinking about, as this is the university - at its best. And that is only one small part of a very large, global story. The larger, global story includes all university scholars. We underline the university's long-term potential is measured in decades and centuries. During events, such as a pandemic, long-term idealistic vision can be easy to forget, as many of us are understandably consumed and distracted by real-time cable news cycles and the instantaneous, comforting 
connections in the 24/7/365 Twitter, Instagram, and IMs that comprise today's social media environment. That acknowledged, what follows is a different way to conceptualize paying attention in this unique, historical moment by putting the scholarship most of us do into perspective.

\section{Engaging the tensions that will be waiting for higher education: post- pandemic}

There are several reasons academics might be tempted to jump with both feet into seeking attention and letting everyone know how we feel and what we are doing during the pandemic. This is not saying that there is no pandemic-related work to be done. This second issue of our journal features an example of introspection and analysis based on the lens of practice theory focused on the stories vividly experienced in the types of settings many of us find ourselves currently working in, by Sjølie, Francisco, Mahon, Kaukko, and Kemmis. In contrast, it is harder not to be skeptical of many across knowledge work, in general, and higher education in particular jumping onto the 'pandemic bandwagon' with little to say and even less to actually contribute. Instead, what about looking past the obvious and using this unique time to reorient to the ideas that have slipped below the surface, fallen off agendas, or faded from intellectual debate and community dialogue? Issues that will not be discussed in our next performance evaluation, are not measured in our institutional metrics, will not be spoken about in a (vice) chancellor's speech, probed in an accreditation visit, and will not be featured in international rankings? These ideas and issues were explicitly underlined as the tensions brought into focus in our initial editorial (Aarnikoivu et al., 2019). With the exception of structural racism and social justice, few of these tensions have been the focus of many scholars understandably preoccupied with the pandemic.

The main reason we highlighted higher education's enduring, transnational global tensions in the first editorial, and return to them explicitly and extensively here, is their persistent and seemingly intractable nature. However, when we wrote the initial editorial, we did not anticipate that we would have a real opportunity, so quickly, to re-think and reconsider our approach to those tensions and honestly assess why higher education has not had far more positive impact in those areas. One important insight that we would offer, after reflecting on this period of potentially transformational flux, is that while we in higher education are good at many things, learning (ironically) within or from extraordinary events is not typically something many of us are famous for or even have experience with. There are of course exceptions, but we point this out because, when collaborating on this editorial, we found ourselves wondering about the extent to which we were aware of the complex structural forces that now shape how we spend most of our time as academic professionals. Those dynamics explain whether we are-or are notfocused on what matters the most. We, along with many colleagues, argue 'the best version of higher education' was not what we were up to - as an institution - as the 
pandemic hit. As Newport (2016), Robertson (2018), and Shahjahan (2015; 2016, see Acknowledgements) theorize, pre-pandemic, many of us had been lulled into a blizzard of fragmented activity, datification, unmoored from institutional or personal potential that could benefit all populations in society, not just some populations. We are not getting a 'do-over' in 2020, but this might be as close as many of us will get in our lifetime.

\section{Time will tell}

The potential of critical reflection and analysis of extraordinary events experienced by ordinary people is nothing new. It is business as usual in many fields. Airline pilots, crews, and air-traffic controllers learn from aircraft crashes, surgical personnel learn from inadvertently killing patients during failed operations and first responders like police, paramedics, and firefighters routinely learn especially through careful analysis of exceptionally extraordinary events.

As we collaborated on this editorial, we noted many of us often do not systematically de-brief as we move forward, as is typical in the fields noted above. Because we often do not, we cannot help but speculate if this is one of the reasons why so many of the tensions we focused on in our initial editorial have not been ameliorated by higher education, even though higher education appears to potentially offer the best leverage, institutionally, organizationally, and professionally on those serious challenges. Perhaps, as Shahjahan (2015) or Bourdieu (1988) both argued, a more profound understanding of time, in part, explains how (or if) scholars define, engage, and even shape the era in which they live for the wider good of society.

What if we, in higher education were better at learning, over time, like pilots or surgical teams or firefighters? What might that look like in higher education? Because many of us have the time to reflect, re-think, refine, and regroup, we, the editors, have firstly (above) done our best to spotlight this unique moment in time. Secondly, we have simultaneously tried to draw attention to contextual and structural issues which explain why it is so easy to miss and why that matters for our journal's audience. Thirdly, (below) we offer a practical conceptualization that illuminates the lack of real pressure many are under in contrast to colleagues, neighbors, friends, and relatives who are directly or indirectly involved in highly visible, but also essential, supporting positions and occupations crucial to getting our societies and communities through the pandemic. Few of us are neither directly nor indirectly in highly visible or even low visibility positions crucial to negotiating the crisis our societies are now engaged, especially during the acute stage and immediate aftermath. That is not good or bad, but that is how it is. 


\section{Conceptualization: why many of us have time to think about this?}

Maybe the emergent structural nature of higher education does not bother you. Perhaps you work in a position where you spend the majority of your time paying careful attention to acute topics, issues, and challenges facing the communities and societies we serve. Maybe you are even making significant strides towards ameliorating the tensions we spotlighted in our first editorial that you do not need to bother with genuflecting to the commercial platforms and the algorithm-driven indexes that frame your country's institutions' research, teaching, social engagement - and perhaps your career path.

In contrast, many of us are in the middle of negotiating precarious positions with short or no funding horizons and do not have free hands when it comes to academic freedom. And many do not have the types of positions where they can ignore the Euro, US and Anglo-centric conceptualizations of time and commercially-driven datafication of knowledge work (Robertson 2018; Shahjahan 2015, see Acknowledgements). In terms of technology, this is very easy to see in the EdTech industry, as they step forward to profit across education, broadly speaking. When upper secondary education and higher education go online, the providers of internet platforms, such as Zoom and Google, are integral, which translates into private profit. Not only can the EdTech industry gain access to large amounts of data that they now can profit from, they also have the opportunity to advance their positions in different ways (see Klein, 2007; Saltman, 2016).

It might be the case that your position is secure, or the opposite; that you understand the relationship between power and (your) time, data, and institutional metrics, or have not really thought about it. Especially those two structural tensions have led our team to reflect that all of us, in higher education, have an unprecedented opportunity to critically reflect on what we-collectively and individually-hope higher education could be, post-pandemic, in terms of the structural dynamics shaping higher education. For instance, what consequences will the surveillance make possible through all this data have for academics and students within and across countries across the globe? Might it be, as Robertson (2018) and Shahjahan (2015, 2016, see Acknowledgements) suggest, we, as professionals, are losing control over higher education? What happens to countries (neighborhoods and entire groups) outside this surveillance and across the digital class divide (Zakaria, 2020), outside the platforms and ideas about time that structure the vast bulk of our focus and actions? So, rather than give in to shortterm, datafied actions that do not change anything, we offer the following conceptualization to illustrate why we might want to take a beat in a moment of transformational flux analogous to the eye of a hurricane.

There are two key dimensions that put many of us in a conceptually defined space where we may have - for the first time in our lives - a new space and perspective to think about the best version of higher education for those who matter the most. 'Those who matter the most' is different for every individual, operational 
unit, sub-organizational unit, higher education institution, and system. And might people who need us the most be the least likely to directly benefit from our handson action, as scholars?

\section{What is our role? Is our contribution in/visible?}

With regard to the COVID-19 pandemic, most people can ask themselves, in a professional sense: 'What is the nature of my role?' (in the pandemic) and 'are my efforts visible or invisible? (in the pandemic). In other words, there are two dimensions: roleldegree of involvement and in/visibility that illuminate one way to conceptualize a rudimentary institutional, occupational, professional, or even a societal division of labor.

Like all typologies, this first attempt deals with key qualitative distinctions, broad dimensions, and extremes at the end of spectrums. Because all typologies are abstract oversimplifications, they miss nuance between the extremes. Further work, if any were warranted, could be done by colleagues who could operationalize our rudimentary suggestions into statistical generalizations to defined populations, or relational generalizations, to social networks. That said, for the purposes of broad, qualitative brushstrokes that illuminate an exceptional opportunity, we hope this initial conceptualization suffices to ground our point. Anything beyond that falls outside of the scope of a brief editorial.

\begin{tabular}{|l|l|l|l|}
\hline $\begin{array}{l}\text { Role and visibility in } \\
\text { the COVID pandemic }\end{array}$ & $\begin{array}{l}\text { Role: degree and nature of } \\
\text { involvement in the } \\
\text { pandemic }\end{array}$ \\
\cline { 2 - 4 } & $\begin{array}{l}\text { Indirect } \\
\text { 'hands off' }\end{array}$ & $\begin{array}{l}\text { Direct 'hands } \\
\text { on' }\end{array}$ \\
\hline \multirow{2}{*}{$\begin{array}{l}\text { Visibility in } \\
\text { the pandemic }\end{array}$} & $\begin{array}{l}\text { Highly } \\
\text { visible }\end{array}$ & $\begin{array}{l}\text { Indirect } \\
\text { Highly visible }\end{array}$ & $\begin{array}{l}\text { Direct } \\
\text { Highly visible }\end{array}$ \\
\cline { 2 - 4 } & Invisible & $\begin{array}{l}\text { Indirect } \\
\text { Invisible }\end{array}$ & $\begin{array}{l}\text { Direct } \\
\text { Invisible }\end{array}$ \\
\hline
\end{tabular}

Table 1. Conceptualizing 'role' and 'visibility'

Hands-on and highly visible professionals: the professionals who save lives At the risk of stating the obvious, we all know who these professionals are and why they are highlighted first. They are the hands-on emergency room doctors, paramedics, intensive care doctors, nurses, aides, and technicians. These people, in short, may end up saving your life if you end up on the wrong side of the pandemic. Despite their highly visible role, they by and large are not seeking, nor do they want attention. There is a lesson in their professional reality for those willing to learn it. They make their living paying attention - to you and I.

To the extent that research scientists are directly engaged in the race for a vaccine, therapeutics, better forms of diagnostic testing, they are also 'hands on', 
but in a different way. If and when they are successful — or they fail — it is highly visible, but like those directly in harm's way, they do not have time to think about visibility. If it comes, it is long after completing the task at hand.

Hands-on, but often invisible: the essential workers whose work allows yours

Society's essential workers are equally important, for example, mass transit drivers, food market cashiers, pharmacists, internet service providers, public utility employees, plumbers, electricians. Pre-pandemic, this was often an invisible, underappreciated set of roles. During the pandemic these ordinary people have been asked to expose themselves, hands-on, to extraordinary risks. Many of them have cheerfully shown up, but it has come at a lethal price - for all of society, in general, and for far too many of them, in particular.

Hands-off, but highly visible: key actors with key contributions

While not on the front lines, people in leadership positions in government service and key industries, some political, some civil authorities, some professionals are in highly visible, crucial positions, especially when it comes to public policy debate, decisions, direction, and execution of public policy, government-industry cooperation, and the use of society's resources. In addition, journalists covering the pandemic are often highly visible and the reason we understand the topic to the extent that we can. Where societies have fared well, it is because of exceptional leadership and process-driven decision-making, as well as those who cover it in critical media. The opposite is unfortunately as true.

Hands-off and invisible: or 'most people', including most scholars

In the response to COVID-19, the role many readers of this journal have not been directly involved in a hands-on or critical supporting and visible role of those who are in harm's way. The exception might be readers supporting colleagues, in some form in the life sciences and university hospitals. A similar, easy to miss and crucial role may very well have been to many colleagues, scholars, and others who drew support from our scholarship in ways that turned out to be very important, yet invisible.

That acknowledged, with respect to COVID-19, some of us might have felt uncomfortably invisible. Many people in other domains are in a similar, bystander role. The best real contribution we might make? Washing our hands, socially distancing, wearing a facemask in public. This can sometimes feel quite unimportant. Many of us wish we could do more and there are small acts we can do. They do not quite stack up to what others have their hands full with, just now. However, we are arguing this is not a bad thing, if we use this time to pay attention to the very real potential we have to act, if we only recognize it as such. 


\section{The potential of transformational flux for higher education}

During this historical moment of transformational flux, invisibility, with a more profound appreciation and understanding of time, along with structural power dynamics, might actually be a good thing. This moment is a set of circumstances that can be put in perspective, which is what we have done our best to do in these few pages. The easiest way to do use this time might be to reflect more carefully on the wicked problems we have always been focused on. We could assume visible, hands-on roles in higher education's biggest challenges - especially those who tend to be ignored by some in positions of power. There are parts many of us have yet to play, where we could be doing better. Perhaps, a lot better. Is there really anything preventing us from doing this?

In higher education, the tensions we cited in our inaugural editorial offer numerous, unmet challenges in acute need of direct, hands-on roles, analogous to those we see battling COVID-19 on the news. This has tragically been underlined during the pandemic, in the US and around the globe regarding the lethal structural racism where unarmed black people are killed by armed police. While this topic might seem far away and unimaginable to many scholars, the magnitude of the global resonance and reaction to social justice issues in our communities was difficult to miss for anyone paying attention. The question that arises is whether we, in higher education, engage those challenges or remain silent and on the sidelines? Many in higher education across the US are currently asking if higher education could be playing a more constructive role in social justice issues. We wonder if the same questions might be every bit as relevant in our own societies? This is only one issue, but it is inextricably related to the wider neo-colonialization of knowledge work (Robertson, 2018; Shahjahan, 2016) that might be happening because seeking attention - inside the box and by feeding the algorithmic metrics - is the now the fastest route to promotion and tenure in the systems where several of us work. This moment offers us a chance to ask ourselves if that is really the legacy we want to define our collective contribution to university scholarship?

It is natural to want to help during a once-in-a-generation challenge. Contemporary social media networks and commercial media platforms framing our actions and reinforcing fragmented activity offer us plenty of 'as if' opportunities for activity that in many cases has nothing to offer that outweighs washing your hands, using a facemask, and social distancing.

Around the world, the practicalities of scheduling fall semester 2020 rest uneasily against larger questions about the relevance and responsiveness of higher education in the $21_{\mathrm{st}}$ century. This is thrown into sharp relief, especially when contrasting essential workers risking their lives daily, while many highly educated elites shelter or are trapped in place. The biggest risk many of us face? Whether or not our internet service providers allow us to connect with our global web of colleagues. As Zakaria (2020) wrote recently in the Washington Post, postpandemic comparative analyses of who was most negatively affected during the pandemic will probably underline that it was not us (cosmopolitan, highly educated 
knowledge workers). However, critically appreciating this moment of flux might also reveal insights that highlight an easily overlooked potential, as to what higher education's most essential contribution to a post-COVID society might look like. That type of society includes understanding those across our countries and in our communities whose life and livelihood has been fundamentally altered, while bearing the brunt of the risk and the negative consequences. It is easy to understand why those groups hardest hit might view highly educated hyper-connected expert elites with suspicion. That said, the role higher education now has the chance to play in bridging global, intersectional tensions is worth paying attention to, if for no other reason than we can. Zakaria's editorial did not engage that point or potential, but we argue that we-all scholars - are now in the position to do precisely that.

David Hoffman, Melina Aarnikoivu, Petra Angervall, Catarina Player-Koro, and Kathleen Mahon

\section{Acknowledgements}

We are deeply indebted to the scholarship of and ongoing conversations with Riyad Shahjahan who works at Michigan State University (USA). Discussions about Riyad's theorizations of time, space, and affect, as well as the role datafication is increasingly playing in higher education have heavily influenced our argumentation. 


\section{References}

Aarnikoivu, M., Mahon, K., Agnafors, M., Hoffman, D., \& Angervall, P. (2019). Another higher education journal: Really? Journal of Praxis in Higher Education, 1(1), 1-9.

Bourdieu, P. (1988). Homo Academicus. Cambridge: Polity.

Gordon-Levitt, J. (2019). How craving attention makes you less creative. Ted Talk. Accessed: 5 July, 2020 at:

https://www.ted.com/talks/joseph_gordon_levitt_how_craving_attention_ makes_you_less_creative?language $=$ en

Klein, N. (2007). The shock doctrine: the rise of disaster capitalism (1st ed.). New York: Metropolitan Books/Henry Holt.

Newport, C. (2016). Deep work: Rules for focused success in a distracted world. London: Piatkus.

Robertson, S. (2018). Platform capitalism and the new value economy in the academy. Working Paper Series. CULTURE, POLITICS AND GLOBAL JUSTICE RESEARCH CLUSTER. Cambridge. Accessed: 5 July, 2020 at: https://cpgj.files.wordpress.com/2018/04/cpgj-workingpaper-12.pdf

Saltman, K. (2016). Capitalizing on disaster: Taking and breaking public schools. NY: Routledge.

Shahjahan, R. A. (2015). Being 'lazy' and slowing down: Toward decolonizing time, our body, and pedagogy. Educational Philosophy and Theory, 47(5), 488-501. DOI: 10.1080/00131857.2014.880645.

Shahjahan, R. A. (2016). International organizations (IOs), epistemic tools of influence, and the colonial geopolitics of knowledge production in higher education policy. Journal of Education Policy, 31(6), 694-710. DOI: 10.1080/02680939.2016.1206623.

Zakaria, F. (2020). Experts have jobs. They need to understand those who don't. Opinion Column. Washington Post. May 15, 2020 at 2:22 a.m. GMT+3. Accessed on 6 July, 2020 at: https://www.washingtonpost.com/opinions/experts-have-jobs-they-needto-understand-those-who-dont/2020/05/14/e715e534-9620-11ea-91d7cf4423d47683_story.html 